Eliane Corrêa da Rocha

\title{
O Aspecto Social da Iconografia do Futebol e Estudo de Caso das Agremiações Desportivas Cariocas
}

Dissertação de Mestrado

Dissertação apresentada como requisito parcial paraobtenção do título de Mestre pelo Programa de Pós-Graduação em Design do Departamento de Artes e Design do Centro de Teologia e Ciências Humanas da PUC-Rio..

Orientador: Prof. Alberto Cipiniuk

Rio de Janeiro

Abril 2008 
O Aspecto Social da Iconografia do Futebol e Estudo de Caso das Agremiações Desportivas Cariocas

Dissertação apresentada como requisito parcial paraobtenção do título de Mestre pelo Programa de Pós-Graduação em Design do Departamento de Artes e Design do Centro de Teologia e Ciências Humanas da PUC-Rio..

Prof. Dr. Alberto Cipiniuk Orientador

Departamento de Artes \& Design - PUC-Rio

Profa. Dra. Vera Lucia Nojima Departamento de Artes \& Design - PUC-Rio

Prof. Dr. Ricardo Gomes Lima Instituto de Artes - UERJ

Prof. Dr. Paulo Fernando Carneiro de Andrade Coordenador Setorial do Centro de Teologia e Ciências Humanas - PUC-Rio

Rio de Janeiro, 04 de Abril de 2008 
Todos os direitos reservados. É proibida a reprodução total ou parcial do trabalho sem autorização da universidade, da autora e do orientador.

\section{Eliane Corrêa da Rocha}

Graduou-se em Desenho Industrial (Programação Visual) pela UFRJ (Universidade Federal do Rio de Janeiro), em 1996. Especializou-se em design gráfico pelo Pratt Institute, Nova York, 1998, e em Marketing pelo IAG/PUC-Rio, 2002. Atua na área de design gráfico.

Ficha Catalográfica

Rocha, Eliane Corrêa da

O aspecto social da iconografia do futebol e estudo de caso das agremiações desportivas cariocas / Eliane Corrêa da Rocha ; orientador: Alberto Cipiniuk. - 2008.

155 f. : il. ; $30 \mathrm{~cm}$

Dissertação (Mestrado em Artes e Design)Pontifícia Universidade Católica do Rio de Janeiro, Rio de Janeiro, 2008.

Inclui bibliografia 
À pequena Manuela, "compreensiva" quanto à minha ausência, e fonte de inspiração nos dois anos que completa juntamente com a conclusão do mestrado.

Ao Alexandre, rubro-negro apaixonado e presença fundamental na minha vida, por seu afeto e sua imensurável contribuição ao conteúdo desta pesquisa.

À minha amiga e mãe, Denise, pelo apoio imprescindível para a finalização deste curso e pelas importantes sugestões e contribuições ao meu estudo.

Ao meu querido pai, Luis Paulo, pelo convívio, apoio e interesse na minha pesquisa, e por ter me proporcionado condições para que eu chegasse a este momento.

Ao torcedor do América, vovô Aldir (in memoriam), presença para sempre especial na minha vida. 


\section{Agradecimentos}

Ao meu orientador, Professor Alberto Cipiniuk, pela fundamental contribuição ao desenvolvimento do trabalho, pelas valiosas reflexões, e pelas instigantes aulas a que tive o prazer de assistir durante o curso.

Ao $\mathrm{CNPq}$ e à PUC-Rio, pelos auxílios concedidos, fundamentais para a realização deste trabalho.

Aos professores doutores que gentilmente aceitaram o convite para participar da banca examinadora: Ricardo Gomes Lima Vera Nojima e Nilton Gamba Jr.

À Zelia Seiblitz, pelos pertinentes comentários e pela palavra amiga sempre presente durante a atenta leitura desta dissertação.

Ao professores Antonio Edmilson Rodrigues, Antonio Jorge Soares, Bernardo Buarque de Holanda, Jorge Helal e Victor Mello Lopes pelas valiosas indicações bibliográficas para a minha pesquisa.

Aos professores das aulas de mestrado, que muito contribuíram para o meu trabalho, em especial Claudio Magalhães, Denise Portinari, Leandro Konder, Luis Antonio Coelho, Margarida de Souza Neves, Vera Nojima e Vera Damazio.

Ao professor Roberto Vershlaisser, que durante a graduação na UFRJ, despertou meu interesse pelo ícones das manifestações populares

Aos colegas de trabalho da PUC, em especial aos professores Artur Braga e Luiz Fernando Azevedo, pela compreensão durante todo o período em que tive as atenções divididas. 
A Pablo Barroso, Bárbara Nieck, Tiago Cambará, Marcos Carvalho, André Gomes, Flávia Rocha e Rosa Maria, pela significativa contribuição a esta pesquisa.

Ao meu querido irmão, Rodrigo Rocha, por seu carinho, sua disponibilidade e seus comentários oportunos e de grande valia.

À Anna Maria Castro Santos, pela dedicação e envolvimento integral durante a revisão deste trabalho.

Aos jornalistas Claudio Nogueira, Luis Mendes e ao botafoguense Roberto Porto, pela generosidade durante as valiosas entrevistas.

Aos integrantes do "Loucos por futebol" Marcelo e Celso, e ao jornalista Hans Hemming, pela atenção dispensada.

Aos professores, amigos, funcionários e colegas da PUC-Rio e a todos que de alguma forma contribuíram para a realização deste projeto.

A toda a minha família e a meus amigos, pelo constante incentivo. 


\section{RESUMO}

Da Rocha, Corrêa Eliane: Cipiniuk, Alberto. O Aspecto Social da Iconografia do Futebol e Estudo de Caso das Agremiações Desportivas Cariocas. Rio de Janeiro, 2008. 155 p. Dissertação de Mestrado. Departamento de Artes e Design, Pontifícia Universidade Católica do Rio de Janeiro.

É notória a relevância do futebol. Praticado em âmbito mundial, envolve particular grau de participação e envolvimento emocional da população brasileira, podendo-se ainda destacar nesse contexto o futebol carioca como o mais tradicional do Brasil. O presente estudo procura desenvolver os aspectos do design nesse esporte, principalmente nas associações centenárias cariocas fundadas ao final do século XIX e início do XX, em especial aquelas do Rio de Janeiro, fortemente representativas de inúmeros torcedores brasileiros: Botafogo, Flamengo, Fluminense e Vasco. Buscamos interpretar a iconografia presente nesse domínio, bem como a dimensão simbólica corporificada na identidade visual e nos uniformes das agremiações de futebol.

Sob essa perspectiva, apresentamos a importante influência do viés social e cultural, por exemplo, na caracterização das cores das principais agremiações esportivas cariocas. Neste estudo privilegiamos a noção de que o processo de construção social expresso através das cores, bandeiras e símbolos gráficos produziu um sistema de imagens identitárias extremamente importante, em detrimento da consideração de aspectos meramente técnicos e estéticos

Importa analisar o sentido de certas escolhas gráficas, e o modo pelo qual estas formas produzem novos códigos, acarretando diversificação do universo material e simbólico. Mais do que respostas, esta análise pretende levantar perguntas sobre a origem de tais escolhas gráficas. Por que a maioria dos clubes de futebol é representada por um escudo? Por que os uniformes são representados por listras? Qual a articulação entre a emblemática da cidade e o esporte? Como se dá na contemporaneidade o impacto da dimensão simbólica da identidade visual e das camisas dos clubes de futebol?

\section{Palavras-chave}

Design gráfico, iconografia, social, cultural, futebol , Rio de Janeiro. 


\section{Abstract}

Da Rocha, Corrêa Eliane: Cipiniuk, Alberto. The social aspect of soccer iconography and a case study of Rio de Janeiro's premiere league teams. Rio de Janeiro, 2008. 155 p. Dissertação de Mestrado. Departamento de Artes e Design, Pontifícia Universidade Católica do Rio de Janeiro.

The relevance of soccer to Brazilian culture is well known. It is undisputed as a national sport, and it involves a high degree of participation and emotional investment by Brazil's population. The study presented here looks to take the sport into the field of design. I seek to interpret the symbolic dimension embodied by the visual identity and the uniforms of Rio's soccer teams. The object of my study is the iconography that represents Rio de Janeiro's premiere league teams: Botafogo, Flamengo, Fluminense and Vasco.

In this study I will attempt to gauge the process of social construction expressed in the teams' colors, flags, and graphic elements that produced an extremely important iconographic language that goes beyond the mere technical and aesthetic scope of design.

It is important to analyze the choice of certain graphic vocabularies, and the way by which these vocabularies produce a new visual code and a diversification of symbolic language. More than answers, this analysis intends to raise questions about the origin of this iconography.

Why are the majority of soccer teams represented by a shield? Why do the uniforms have stripes? How do the city's symbols relate to each teams' logos? What is the impact of the teams' symbolic dimension, logos, colors and other visual elements on contemporary society at large?

\section{Keywords}

Iconography, Graphic Design, Social, Cultural, Soccer, Rio de Janeiro 


\section{Súmario}

Introdução

8

1 A Dimensão "sagrada" representada no uniforme e na identidade visual do futebol carioca

2. A legitimação das formas gráficas 33

2.1 Estruturas de superfície e padrões gráficos aplicados 47

2.2 Listras do Remo $\quad 52$

2.2.1 Goleiros, árbitros, hinos e campos 63

$\begin{array}{lll}2.3 & \text { O Simbólico dos Números } & 67\end{array}$

$\begin{array}{lll}2.4 & \text { O Escudo } & 74\end{array}$

$\begin{array}{lll}2.4 .1 & \text { Origens } & 81\end{array}$

2.5 O sistema heráldico 82

2.6 Os formatos do escudos 82

$\begin{array}{lll}2.7 & \text { Bandeiras, tipografias e mascotes } & 87\end{array}$

$3 \quad$ Estudo de caso dos Clubes de Futebol Cariocas 90

$\begin{array}{lll}3.1 & \text { Os aspectos gráficos do Turfe } & 94\end{array}$

3.2 A ldentidade Visual dos Clubes de Regatas 99

3.3 A Estrela do Botafogo 105

3.3.1 As cores do Botafogo 112

3.5 A Cruz - Símbolo do Vasco 115

3.6 CR Flamengo - O Rubro - Negro 121

$\begin{array}{ll}\text { 3.6.1 O Vermelho } & 125\end{array}$

3.6.2 Flamengo: Primeiras Competições, Vitórias e Mudanças 126

3.7. Fluminense Football Club - O Tricolor 128

3.7.1 O Verde, o Grená e o Branco 132

3.8 Utilização dos signos para reforçar a identificação com as tradições 136

3.9 Outras Agremiações Cariocas 140 Conclusão 142

$\begin{array}{lr}\text { Referências Bibliográficas } & 148\end{array}$ 